\title{
PROGRAM EMAS DALAM KONTROL GULA DARAH PENDERITA DIABETES MELLITUS TIPE 2
}

\author{
Arief Andriyanto $^{1,3)}$, Etty Rekawati²), Dwi Cahya Rahmadiyah²) \\ ${ }^{1)}$ Mahasiswa Spesialis Keperawatan Komunitas, Universitas Indonesia \\ ${ }^{2)}$ Departemen Keperawatan Komunitas, Fakultas Ilmu Keperawatan, Universitas Indonesia \\ ${ }^{3)}$ STIKes Bina Sehat PPNI Mojokerto, Jawa Timur
}

Email: ners.arif91@gmail.com

\begin{abstract}
Abstrak
Latar Belakang: Diabetes melitus merupakan penyakit tidak menular yang termasuk dalam kategori penyakit kronis dan diperkirakan akan meningkat, sehingga perlu dilakukan pengendalian metode yang direkomendasikan oleh Kementerian Kesehatan dalam bentuk penanganan yang cerdas terhadap diabetes melitus. Layanan ini bertujuan untuk menganalisis pengaruh program EMAS terhadap pengendalian gula darah orang dewasa penderita diabetes melitus tipe 2. Metode: intervensi selama 6 bulan. Sampel penelitian sebanyak 86 orang dewasa penderita diabetes melitus tipe 2 di Cisalak Pasar Kecamatan Ciamnggis Kota Depok. Hasil: Kontrol gula darah orang dewasa dengan diabetes melitus tipe 2 melalui intervensi EMAS (p-value 0,001 <0,05). Kesimpulan: Perubahan perilaku orang dewasa dengan diabetes melitus tipe 2 diperlukan untuk menstabilkan gula darah pasien. Oleh karena itu, peran komunitas perawat spesialis sangat diperlukan untuk memberikan intervensi sesuai dengan kebutuhan penderita diabetes melitus untuk penanganan penyakitnya.
\end{abstract}

Kata kunci: intervensi EMAS; Kontrol glukosa; Diabetes melitus tipe 2

Abstract

Background: Diabetes mellitus is a non-communicable disease that is included in the category of chronic diseases and will be expected to increase, so it is necessary to control the method recommended by the Ministry of Health in the form of clever management of diabetes mellitus. This service aims to analyze the effect of the EMAS program on adult blood sugar control with type 2 diabetes mellitus. Method: intervention for 6 months. Samples were 86 adults with type 2 diabetes mellitus in Cisalak Pasar, Ciamnggis District, Depok City. Results: Adult blood sugar with type 2 diabetes mellitus was controlled through EMAS intervention (p-value $0.001<0.05$ ). Conclusion: Changes in the behavior of adults with type 2 diabetes mellitus are needed to stabilize the patient's blood sugar. Therefore, the role of the specialist nurse community is needed to provide interventions by the needs of people with diabetes mellitus to manage the disease.. Keywords: Intervention EMAS;Glucose control; Type 2 diabetes mellitus

Keywords: Intervention EMAS;Glucose control; Type 2 diabetes mellitus

\section{PENDAHULUAN}

International Diabetes Federation (IDF) memiliki data estimasi pada tahun 2015 terdapat 415 juta jiwa terdiagnosis penyakit diabetes melitus di dunia, dan diperkirakan pada tahun 2040 mengalami peningkatan menjadi 642 juta jiwa. Laporan Organisasi Kesehatan Dunia, diperkirakan pada tahun 2004 sekitar 194 juta diabetisi akan mencapai 333 juta diabetisi di tahun 2025, dengan populasi terbanyak berada di Asia dan Oseania [1], [2]. Penderita diabetes di Asia Tenggara pada tahun 2015 presentase orang dewasa dengan diabetes melitus sebanyak $8,5 \%$ [3]. Indonesia juga menyumbangkan prevalensi yang cukup besar terkait jumlah diabetisi dari tahun 2007, 2013, dan 2018 mengalami peningkatan, yang dapat dilihat dari data Riset Kesehatan Dasar (Riskesdas) bahwa sebanyak 5,7\% di tahun 2007, 6,9\% di tahun 2013 dan menjadi 8,5\% di tahun 2018.

Penyakit ini dapat dikendalikan dengan perilaku manajemen diri seperti pemberian edukasi kesehatan, manajemen nutrisi (perencanaan makan atau diet), aktivitas fisik yang teratur untuk mengurangi kelebihan berat badan, intervensi farmakologis yaitu minum obat/insulin secara teratur, pemantauan secara rutin kadar gula darah, melakukan perawatan kaki, dan pengelolaan stres [4]-[6]. Mempertahankan kadar glukosa darah dalam batas 
normal sangat penting dalam pengelolaan diabetes melitus. Diet merupakan cara yang dapat memiliki dampak yang besar dalam menstabilkan kadar glukosa darah diabetisi [7]. Hasil penemuan terbaru dalam sebuah penelitian yang didasarkan pada teori sosial-kognitif, menemukan bahwa selfefficacy pada wanita diabetes melitus lebih efektif dalam meningkatkan aktivitas fisik [8]. Penelitian yang dilakukan mengenai faktor-faktor yang berpengaruh terhadap self-management diabetisi tipe 2 pada orang dewasa di Kota Malang Jawa Timur dengan hasil dapat meningkatkan efikasi diri dan kesadaran diri diabetisi untuk mencapai perilaku manajemen diri yang baik, seperti memiliki diet sehat, berolahraga secara teratur, aktif memantau kadar gula darah, meminum obat secara teratur dan melakukan perawatan kaki [9]. Penelitian terkait pendidikan kesehatan didapatkan Diabetes selfmanagement education (DSME) memainkan peran kunci dalam memberdayakan orang dengan diabetes untuk terlibat dan mempertahankan perubahan gaya hidup, yang telah terbukti meningkatkan hasil kesehatan. DSME adalah proses memfasilitasi pengetahuan, sikap, dan kemampuan yang diperlukan untuk manajemen diri [10].

Hasil dari berbagai penelitian menyatakan bahwa intervensi keperawatan telah berfokus pada pilar penatalaksanaan diabetes melitus, yang artinya dibutuhkan suatu inovasi bagi penyedia layanan khususnya untuk mendidik diabetisi tentang kebutuhan akan perawatan pencegahan yang tepat melalui pendekatan berbasis komunitas [11]. Kegiatan promosi kesehatan dalam banyak penelitian telah dinyatakan sebagai penentu perilaku seseorang, oleh karena itu promosi kesehatan akan menjadi faktor penting dalam mempromosikan perilaku sehat [12], [13]. Pelayanan yang diberikan secara komprehensif dan berkualitas membutuhkan suatu pengembangan untuk dapat menggambarkan promosi kesehatan untuk mendukung dewasa dengan diabetes mellitus dalam berperilaku [14].

Upaya yang dilakukan harus menekankan pada penatalaksanaan diabetes melitus secara keseluruhan, seperti Edukasi, Manajemen nutrisi, Aktivitas fisik, pengelolaan Stres yang dikemas dalam bentuk intervensi EMAS. Intervensi juga dilakukan dengan mengembangkan suatu alat media. Media yang digunakan dalam intervensi dapat berupa modul pembelajaran dan buku saku diabetes melitus untuk mempermudah diabetisi mendapatkan informasi kesehatan [15], [16]. Pengembangan modul ini ditujukan untuk dapat meningkatkan kesadaran diabetisi agar dapat merubah gaya hidup menjadi lebih sehat sehingga dapat memperbaiki perilaku dalam mengontrol berat badan, lingkar pinggang, tekanan darah, dan yang paling utama dapat mengontrol kadar gula darah, sehingga menjadikan diabetisi mampu melakukan pengendalian penyakit diabetes melitus [17]. Penelitian ini bertujuan untuk menganalisis efektifitas intervensi keperawatan EMAS terhadap perubahan perilaku dan kontrol gula darah dewasa dengan diabetes mellitus tipe 2 .

\section{MASALAH, TARGET, LUARAN}

Penyakit ini mengalami peningkatan dari 1,7

menjadi 2,2 juta yang disebabkan oleh faktor risiko seperti penggunaan tembakau (merokok), diet tidak sehat, kurang aktivitas fisik, dan penggunaan alkohol, terutama di Indonesia negara berpenghasilan rendah dan menengah bahwa prevalensi diabetes telah meningkat hampir dua kali lipat sejak tahun 1980 [18]. Penyakit diabetes melitus akan bertambah menjadi masalah yang serius apabila diabetisi memiliki gaya hidup yang tidak sehat seperti mengkonsumsi makanan tinggi lemak dan gula, serta tidak dapat mempertahankan berat badan yang ideal [19].

Hasil survei di Wilayah Kerja UPF Puskesmas Cisalak Pasar Kecamatan Cimanggis Kota Depok pada 86 pasien diabetes mellitus, didapatkan rerata usia pasien 49 tahun, jenis kelamin laki-laki $25,6 \%$ dan 74,4\% jenis kelamin perempuan, sebagian besar pendidikan SMP 40,7\% dan pekerjaan sebagai ibu rumah tangga, serta 40,7\% sumber informasi yang didapat pasien dan keluarga terkait informasi penyakit diabetes mellitus melalui media (TV/Radio/Internet/Koran). Data pengetahuan pasien terkait penyakit diabetes mellitus terdapat $11,6 \%$ pengetahuan baik, $46,5 \%$ pengetahuan cukup, $41,9 \%$ pengetahuan kurang, 40,6\% kesadaran diri tinggi, $59,4 \%$ kesadaran diri rendah, 39,5\% self-efficacy tinggi, $60,5 \%$ self-efficacy rendah, $43 \%$ sikap positif, $57 \%$ sikap negatif, $45,3 \%$ keterampilan baik dan $54,7 \%$ keterampilan buruk (Data Survei Komunitas, 2018).

Faktor risiko kejadian diabetes melitus juga ditemukan, antara lain jenis kelamin, usia > 45 tahun, kelebihan berat badan dan obesitas, BMI $>30 \mathrm{~kg} / \mathrm{m} 2$, tekanan darah tinggi, pola tidur, serta indeks masa tubuh [20]-[22]. Indeks masa tubuh yang tidak ideal dialami oleh diabetisi ini disebabkan oleh kurangnya melakukan aktivitas fisik, tingginya mengkonsumsi karbohidrat, protein dan lemak yang memicu terjadinya obesitas. Penyakit diabetes melitus dapat dicegah, dan dikontrol dengan mengendalikan faktor risiko, maka sangat diperlukan program pengendalian diabetes melitus (Trisnawati \& Setyorogo, 2013). Target pengabdian masyarakat ini menekankan pada program pengendalian faktor risiko penderita melalui pendekatan berbasis komunitas dan keluarga yaitu Community as Partner, Family Centered Nursing, Maglaya, Health Promotion Model terhadap peningkatan self-awareness, self-efficacy dan perubahan perilaku yang melihat faktor biologis diabetisi tipe 2 terlebih dahulu dan faktor interpersonal dari penyedia layanan kesehatan dalam hal ini pelayanan Posbindu PTM [11]. 
Pemberian intervensi EMAS ini dapat memberikan manfaat bagi pelayanan kesehatan untuk menjadi dasar dalam menjalankan suatu program kesehatan yang disesuaikan dengan kebutuhan klien dalam hal ini diabetisi yang membutuhkan akan penatalaksanaan penyakit DM dengan cara memasukkan kegiatan penyebaran informasi kesehatan pada setiap kegiatan yang ada di Puskesmas dengan menggunakan berbagai macam media pembelajaran dan metode edukasi secara komprehensif, sehingga dalam pemberian asuhan keperawatan keluarga dan komunitas dapat menentukan intervensi yang tepat dan sesuai dengan kebutuhan penderita DM. Hasil dari pelaksanaan intervensi keperawatan EMAS juga dapat dijadikan evidence based practice nursing dalam memberikan asuhan keperawatan pada individu, keluarga, kelompok, maupun komunitas tanpa mengabaikan faktor penentu keberhasilan intervensi

\section{METODE}

PELAKSANAAN

Penelitian ini dilakukan di Kelurahan Cisalak Pasar Kecamatan Cimanggis Kota Depok. Study Design Quasi Experiment Pre-Post Test Without Control Group Design selama 6 bulan, Oktober 2018 - Maret 2019. Teknik pengambilan sampel dalam penelitian menggunakan teknik sampling purposive sampling yang didapatkan jumlah sampel sebanyak 86 responden dan sesuai dengan kriteria dan tujuan penelitian [24]. Sampel dalam penelitian ini memiliki kriteria inklusi, antara lain; 1) klien dengan diagnosa medis diabetes melitus tipe 2 yang didapatkan dari buku registrasi Puskesmas Cisalak Pasar; 2) usia dewasa (35 - 59 tahun); 3) mampu baca tulis. Kriteria eksklusi sampel pada penelitian ini adalah klien dengan komplikasi kaki diabetik dan klien yang tirah baring. Uji statistik untuk seluruh analisis dengan tingkat kemaknaan 95\% (alpha 0,05). Uji statistik parametrik yang digunakan untuk menguji perbedaan beda dua mean dependen berpasangan menggunakan uji paired t test [25].

Pemberian intervensi, sebagai berikut: sesi 1 terkait edukasi kesehatan penyakit diabetes mellitus dengan metode menonton video edukasi, diskusi dan evaluasi buku kerja yang dilaksanakan 1 kali pertemuan pada bulan November minggu pertama (media intervensi: video edukasi, leaflet, lembar balik), pelatihan kader kesehatan dalam penerapan sistem 5 meja posbindu PTM dilakukan 1 kali pelatihan dan 2 kali supervisi.

\begin{tabular}{|c|c|c|c|c|}
\hline Variabel & Mean & SD & $95 \%$ CI & $\underset{\text { value }}{p}$ \\
\hline \multicolumn{5}{|l|}{ Pengetahuan } \\
\hline Sebelum & 12.01 & \multirow{2}{*}{2.020} & $(-8.015)-$ & \multirow{2}{*}{$0.001 *$} \\
\hline Sesudah & 19.59 & & $(-7.148)$ & \\
\hline \multicolumn{5}{|l|}{ Sikap } \\
\hline Sebelum & 22.14 & \multirow{2}{*}{5.315} & $(-12.360)-$ & \multirow{2}{*}{$0.001 *$} \\
\hline Sesudah & 33.36 & & $(-10.081)$ & \\
\hline
\end{tabular}

Keterampilan
Sesi 2: Skrining kesehatan: skrining faktor risiko diabetes mellitus dengan metode support group oleh kader kesehatan kepada masyarakat, demonstrasi dan re-demonstrasi pada pelatihan pengisian google form pada kader kesehatan yang dilaksanakan 2 kali pertemuan pada bulan November minggu kedua dan Januari minggu pertama (media intervensi: form skrining DM, google form, laptop dan LCD).

Sesi 3-5: Manajemen nutrisi: a) makanan sehat dan tidak sehat pasien DM dengan metode permainan kuis siapa berani dan evaluasi buku kerja yang dilaksanakan 2 kali pertemuan pada bulan November minggu ketiga dan keempat (media intervensi: power point, gambar contoh makanan, sterofoam, panduan permainan, print out ppt, bulpoint dan push pin), b) menghitung kebutuhan kalori tubuh dilakukan dengan tutorial yang dilaksanakan 1 kali pertemuan pada bulan Desember minggu pertama (media intervensi: buku kerja), c) menyusun menu makan sehari dengan metode demonstrasi dan re-demonstrasi, sertaevaluasi buku kerja yang dilaksanakan 1 kali pertemuan pada bulan Desember minggu kedua dan evaluasi buku kerja Januari minggu ketiga (media intervensi: buku kerja, food model, piring makananku).

Sesi 6-7: Peningkatan latihan: a) senam kaki diabetes dengan metode demonstrasi dan redemonstrasi yang dilakukan selama 5 kali pertemuan pada bulan Januari minggu pertama, kedua, ketiga dan Februari minggu pertama dan kedua (media intervensi: leaflet, kursi, koran), b) senam cerdik dilakukan bersama kader kesehatan dan masyarakat setiap minggu sekali (media intervensi: sound system, musik senam cerdik gerakan Kota Depok). Sesi 8: relaksasi otot progresif dan terapi musik dilakukan dengan metode pendampingan perawat spesialis keperawatan komunitas selama 5 kali pertemuan pada bulan Februari minggu ketiga sampai dengan Maret minggu ketiga (media intervensi: leaflet, musik instrumental "the give angels" dan sound system).

\section{HASIL}

Hasil dari penerapan inovasi intervensi EMAS terhadap perubahan perilaku dan kontrol gula darah dewasa dengan diabetes mellitus di Kelurahan Cisalak Pasar Kecamatan Cimanggis Kota Depok disajikan dalam tabel 1 dibawah ini.

\begin{tabular}{|c|c|c|c|c|}
\hline $\begin{array}{l}\text { Sebelum } \\
\text { Sesudah }\end{array}$ & $\begin{array}{l}38.59 \\
49.88 \\
\end{array}$ & 9.967 & $\begin{array}{c}(-13.428)- \\
(-9.154)\end{array}$ & $0.001^{*}$ \\
\hline \multicolumn{5}{|l|}{ Gula darah } \\
\hline $\begin{array}{l}\text { Sebelum } \\
\text { Sesudah }\end{array}$ & $\begin{array}{l}238.36 \\
231.63\end{array}$ & 30.490 & $\begin{array}{c}(0.196)- \\
(13.270)\end{array}$ & $0.04 *$ \\
\hline
\end{tabular}

Tabel 2. Keterampilan Kader Kesehatan di Kelurahan Cisalak Pasar Kecamatan Cimanggis Kota Depok, April $2019(\mathrm{n}=14)$ 


\begin{tabular}{lcccc}
\hline Variabel & Mean & SD & 95\% CI & $\begin{array}{c}\boldsymbol{p} \\
\text { value }\end{array}$ \\
\cline { 3 - 4 } \\
Pelatihan Sistem 5 Meja Posbindu PTM \\
Sebelum & 4.29 & 0.745 & $(-4.787)-(-$ & $0.001^{*}$ \\
Sesudah & 8.64 & $3.927)$ & \\
\hline Pembentukan Support Group Dalam Melakukan Skrining \\
DM
\end{tabular}
rerata keterampilan kader kesehatan adalah 4.29 sebelum pelatihan menjadi 8.64 sesudah pelatihan sistem 5 meja posbindu PTM, artinya rerata keterampilan kader kesehatan mengalami peningkatan sebanyak 4.35 , rerata keterampilan kader kesehatan adalah 3.43 sebelum menjadi 8.07 sesudah pembentukan support group dalam melakukan skrining faktor risiko DM, artinya rerata keterampilan kader kesehatan mengalami peningkatan sebanyak 4.64. Hasil uji paired t test didapatkan nilai $p$ value $<0.05$, artinya terdapat pengaruh pelatihan sistem 5 meja posbindu PTM dan pembentukan support group terhadap keterampilan kader kesehatan di Kelurahan Cisalak Pasar Kecamatan Cimanggis Kota Depok.

Tabel 3. Pelatihan Pelaporan Kegiatan Posbindu PTM oleh Kader Kesehatan Menggunakan Google Form di Kelurahan Cisalak Pasar, Kecamatan Cimanggis, dan Dinas Kesehatan Kota Depok, April $\underline{2019}$

\begin{tabular}{lccc}
\hline \multicolumn{1}{c}{ Pelatihan } & n & $\begin{array}{c}\text { Terkirim } \\
(\%)\end{array}$ & $\begin{array}{c}\text { Tidak terkirim } \\
(\%)\end{array}$ \\
\hline Kelurahan Cisalak Pasar & 24 & 87.5 & 12.5 \\
Kecamatan Cimanggis & 120 & 84.2 & 15.8 \\
$\begin{array}{l}\text { Angkatan I Dinkes Kota } \\
\text { Depok }\end{array}$ & 58 & 70.7 & 29.3 \\
$\begin{array}{l}\text { Angkatan II Dinkes Kota } \\
\text { Depok }\end{array}$ & 65 & 100 & - \\
$\begin{array}{l}\text { Angkatan III Dinkes Kota } \\
\text { Depok }\end{array}$ & 52 & 78.8 & 21.2 \\
$\begin{array}{l}\text { Angkatan IV Dinkes Kota } \\
\text { Depok }\end{array}$ & 64 & 92.2 & 7.8 \\
$\begin{array}{l}\text { Angkatan V Dinkes Kota } \\
\text { Depok }\end{array}$ & 54 & 100 & - \\
\hline
\end{tabular}

Berdasarkan tabel 3. pelatihan sistem pelaporan kegiatan posbindu PTM menggunakan google form di Kelurahan Cisalak Pasar, Kecamatan Cimanggis, dan Dinas Kesehatan Kota Depok didapatkan hasil > 70\% peserta pelatihan dapat mengisi dan mengirim data skrining faktor risiko PTM menggunakan google form.

\section{PEMBAHASAN}

Kegiatan promotif dan preventif dengan upaya penyebaran informasi dan edukasi yang efektif melalui strategi intervensi keperawatan komunitas mengenai penyakit diabetes melitus perlu dilakukan, karena edukasi untuk dewasa diabetes melitus merupakan kegiatan yang bertujuan merubah perilaku untuk dapat melakukan pencegahan terjadinya komplikasi akut dan akan mengurangi risiko komplikasi pada jangka panjang [19], [26]. Pengetahuan, sikap, dan keterampilan seseorang akan meningkat apabila dirinya dilakukan pendampingan

\begin{tabular}{crrcc}
\hline Sebelum & 3.43 & & & \\
Sesudah & 8.07 & 1.447 & $(-5.478)-(-$ & $3.807)$ \\
$0.001^{*}$
\end{tabular}

untuk diberikannya suatu kegiatan atau cara menstimulasi dirinya berupa kegiatan-kegiatan yang memicu untuk menimbulkan kesadaran dirinya. Contoh dalam hal ini adalah intervensi berupa EMAS yang dapat diberikan kepada dewasa diabetes mellitus khususnya untuk meningkatkan kesadaran diri dan selanjutnya akan menciptakan manajemen diri yang baik untuk perawatan dirinya. Oleh karena itu, memang dibutuhkan suatu intervensi keperawatan ditatanan pelayanan kesehatan yang diberikan kepada dewasa diabetes melitus tipe 2 dengan upaya promotif dan preventif pengendalian penyakit.

Intervensi yang diberikan kepada dewasa diabetes melitus tipe 2 harus disesuaikan dengan kebutuhan diabetisi agar dapat memiliki manfaat yang bisa dilakukan dalam keseharian dewasa diabetes mellitus. Hal ini dapat dilihat dari hasil uji statistik menggunakan uji paired t test, didapatkan nilai $p$ value sebesar $0,001<0,05$, maka sesuai dasar pengambilan keputusan dapat disimpulkan $\mathrm{H} 0$ ditolak yang artinya terdapat efektifitas penerapan intervensi EMAS (Edukasi, Manajemen nutrisi, Aktivitas fisik, pengelolaan Stres) terhadap peningkatan pengetahuan, sikap, keterampilan, dan kontrol gula darah dewasa diabetes mellitus tipe 2 . Edukasi dengan tujuan promosi hidup sehat perlu dilakukan sebagai bagian dari upaya pencegahan dan pengendalian penyakit diabetes melitus. Asosiasi Diabetes Internasional percaya bahwa untuk mencegah terjadinya komplikasi diabetes atau penyakit semakinberkelanjutan, maka diperlukannya sebuah pendidikan kesehatan terhadap perilaku pengelolan diri diabetisi [13]. Hasil evaluasi latihan 1 buku kerja skor baik $>70$ adalah $83,7 \%$ dan skrining faktor risiko diabetes mellitus tipe 2 kategori sedang $52,3 \%$ dan kategori tinggi 47,7\%. Penelitian terkait pendidikan kesehatan didapatkan Diabetes selfmanagement education (DSME) memainkan peran kunci dalam memberdayakan orang dengan diabetes untuk terlibat dan mempertahankan perubahan gaya hidup, yang telah terbukti meningkatkan hasil kesehatan. DSME adalah proses memfasilitasi pengetahuan, keterampilan, dan kemampuan yang diperlukan untuk manajemen diri. DSME sangat perlu dilakukan kepada diabetisi secara berkala, hal ini juga sudah sejalan dengan program Kementrian Kesehatan [10].

Selain edukasi kesehatan yang diberikan dalam inovasi ini, mahasiswa juga mengajarkan terkait manajemen nutrisi yang meliputi; pola makan, makanan yang dianjurkan, dibatasi, dan dihindari, 
penghitungan kebutuhan kalori tubuh, serta menyusun menu makan sehari. Prinsip pengaturan makan pada diabetisi hampir sama dengan anjuran makan untuk masyarakatumum, yaitu makanan yang seimbang dan sesuai dengan kebutuhan kalori dan zat gizi masing-masing individu. Dewasa diabetes mellitus perlu diberikan penekanan mengenai pentingnya keteraturan jadwal makan, jenis dan jumlah kandungan kalori, terutama pada mereka yang menggunakan obat yang meningkatkan insulin atau terapi insulin itu sendiri [27].

Hasil evaluasi latihan 2 buku kerja didapatkan skor baik > 70 sebanyak $87,2 \%$ terkait makanan yang dianjurkan, dibatasi, dan dihindari. BBI dewasa dengan diabetes mellitus kategori lebih $79,1 \%$ dan kebutuhan kalori minimal 1500 kalori. Intervensi manajemen nutrisi ini juga memiliki hasil yang sama dengan penelitian terkait konseling nutrisi untuk diabetisi tipe 2, dan terbukti dapat meningkatkan pengetahuan responden dan keterampilan dalam menentuksan gizi seimbang [28].

Aktivitas fisik juga diberikan oleh mahasiswa residensi setelah manajemen nutrisi diberikan selama 5 pertemuan. Aktivitas fisik yang dilaporkan oleh Organisasi Kesehatan Dunia dilakukan secara teratur sebanyak 3-5 kali perminggu setidaknya 30 menit, dengan total 150 menit perminggu, dan jeda latihan tidak lebih dari 2 hari berturut-turut. Pada saat melakukan olahraga dianjurkan untuk melakukan pemeriksaan sebelum latihan dimulai [27]. Apabila kadar glukosa darah $<100 \mathrm{mg} / \mathrm{dL}$ pasien harus mengkonsumsi karbohidrat terlebih dahulu dan bila $>250 \mathrm{mg} / \mathrm{dL}$ dianjurkan untuk menunda latihan fisiknya. Kegiatan sehari-hari atau aktivitas sehari-hari bukan termasuk kedalam latihan jasmani. Jenis aktivitas fisik yang baik untuk dewasa diabetes mellitus, diantaranya jogging, berjalan, yoga, bersepeda, berenang, senam aerobik, senam kaki [29].

Aktivitas fisik yang diberikan pada diabetisi berupa senam cerdik dan senam kaki diabetes. Senam cerdik merupakan latihan yang dipelopori oleh Dinas Kesehatan Kota Depok untuk mencegah dan mengendalikan penyakit diabetes mellitus, sedangkan senam kaki diabetes merupakan kegiatan promotif dan preventif yang diberikan kepada diabetisi tipe 2 untuk meningkatkan sensitivitas pada kaki agar dapat mencegah terjadinya komplikasi yaitu luka pada kaki dan melancarkan peredaran darah pada kaki.

Hasil evaluasi buku kerja bahwa 91,8\% dewasa diabetes mellitus dapat melakukan 12 gerakan senam kaki, keluhan kebas sebelum dilakukan intervensi sebanyak $74,4 \%$ menjadi $27,9 \%$ sesudah diberikan intervensi. Terdapat manfaat lain yang dirasakan dewasa diabetes melitus setelah melakukan senam kaki secara teratur. Hal ini dapat dilihat dari hasil penelitian sebelumnya tentang senam kaki, dan didapatkan hasil bahwa terdapat pengaruh senam kaki diabetes terhadap perubahan kadar gula pasien diabetes mellitus tipe 2 diwilayah kerja puskesmas Enemawira [30]. Hasil penelitian juga didapatkan dari penelitian, bahwa didapatkan hasil terdapat pengaruh senam kaki diabetes terhadap nilai Ankle Brachial Index pada pasien diabetes melitus tipe 2 di Rumah Sakit Pancaran Kasih GMIM Manado [31].

Permasalahan dewasa dengan diabetes mellitus adalah resiko terjadinya luka pada kaki sehingga dibutuhkan latihan senam kaki dan biasanya juga dikaitkan dengan peningkatan prevalensi risiko depresi dan kecemasan, yang dapat mempengaruhi kadar glukosa darah, sehingga dibutuhkan cara untuk pengelolaan stress. Peningkatan resiko penyakit diabetes melitus pada kondisi stres disebabkan oleh produksi hormon kortisol secara berlebihan. Produksi hormon kortisol yang berlebih akan berakibat sulit tidur, depresi, tekanan darah naik, yang kemudian akan membuat seseorang menjadi lemas dan nafsu makan berlebih. Maka dari itu diperlukannya metode untuk mengurangi stres yang terjadi [23]. Pengelolaan stres yang efektif dalam menurunkan tingkat stres dan kontrol gula darah diabetes melitus dengan cara latihan relaksasi otot progesif dan terapi musik.

Pengelolaan stres yang dilakukan oleh mahasiswa residensi sejalan dengan program Kementerian Kesehatan yang terkandung dalam program cerdik, yang dimana masyarakat dianjurkan untuk dapat kelola stres dengan baik yang merupakan salah satu edukasi yang dilakukan di berbagai tatanan masyarakat mulai dari sekolah, rumah tangga, tempat kerja, tempat ibadah dan tempat-tempat umum. Tujuan dari Kemenkes terkait anjuran kepada masyarakat agar dapat kelola stres dengan baik adalah agar masyarakat dapat meminimalkan masalah dengan lebih baik untuk tidak menjadikan stresnya menuju kearah timbulnya penyakit.

Hasil evaluasi bahwa rerata kadar gula darah dewasa dengan diabetes mellitus sebelum intervensi adalah 238,36mg/dl menjadi 231,63 sesudah diberikan intervensi dengan skor SD 30,49, yang artinya mengalami penurunan sebesar $30,49 \mathrm{mg} / \mathrm{dl}$. Relaksasi otot progresif memiliki berbagai manfaat, hal ini dapat dilihat dari hasil penelitian sebelumnya terkait pengaruh relaksasi otot progresif didapatkan hasil bahwa latihan relaksasi otot progresif secara bermakna meningkatkan kualitas tidur lansia sehingga dapat dipertimbangkan sebagai terapi komplementer dalam tatalaksana gangguan tidur pada lansia sebagai tindakan mandiri keperawatan [32]. Penelitian yang sama tentang pengaruh terapi 
relaksasi otot progresif juga didapatkan hasil bahwa terapi ini sangat efektif menurunkan stres dan gula darah dengan nilai signifikan 0,003 [33].

Penerapan inovasi EMAS berpengaruh juga disebabkan oleh berbagai macam media dan metode yang digunakan mahasiswa residensi telah terarah dan dapat dimengerti oleh diabetisi berupa modul pembelajaran, buku kerja, leaflet, video edukasi, food model, musik instrumental. Modul pembelajaran sangatlah efektif digunakan sebagai alat bantu mahasiswa residensi dalam memberikan intervensi EMAS kepada dewasa diabetes melitus dan nantinya juga bisa digunakan tenaga kesehatan dalam memberikan pendidikan kesehatan, sedangkan buku kerja diberikan kepada dewasa diabetes melitus untuk sebagai bahan pegangan dan latihan saat intervensi berlangsung.

Modul dan buku kerja ditulis dengan tujuan agar tenaga kesehatan dapat memberikan intervensi yang tepat dan untuk dewasa diabetes melitus dapat belajar secara mandiri setelah mendapatkan arahan dari mahasiswa residensi. Hal ini sependapat dengan penelitian sebelumnya, bahwa dengan memanfaatkan alat media berupa pengembangan modul terhadap tenaga kesehatan, didapatkan hasil yang menunjukkan terdapat reaksi yang sangat positif terhadap pengembangan modul, dan hasil tes pasca pelatihan berupa pengetahuan, sikap, pemantauan, dan evaluasi lebih tinggi dari pada kemampuan tes awal, sedangkan buku kerja yang diberikan kepada dewasa diabetes melitus berguna untuk mempermudah dalam mengerti materi yang akan disampaikan selama intervensi dan menjadikan dewasa diabetes melitus memiliki minat baca yang meningkat [15].

Intervensi EMAS diberikan kepada dewasa diabetes melitus tipe 2 hanya dapat dilakukan oleh perawat spesialis komunitas, yang telah disesuaikan dengan kompetensi perawat berdasarkan munculnya diagnosa keperawatan dari proses asuhan keperawatan. Penerapan inovasi ini menimbulkan suatu diagnosa keperawatan yakni ketidakefektifan manajemen kesehatan, yang membutuhkan berbagai intervensi didalam mengatasinya.

Intervensi yang dapat diberikan berupa EMAS; edukasi diberikan sesuai dengan peran perawat sebagai educator yang akan memberikan informasi kesehatan kepada masyarakat, manajemen nutrisi merupakan pengajaran yang diberikan kepada masyarakat dengan menekankan cara menghitung kebutuhan kalori dan perawat disini dapat berperan sebagai fasilitator, aktifitas fisik berupa senam cerdik dan senam kaki, serta pengelolaan stres berupa relaksasi otot progresif dan terapi musik merupakan terapi modalitas dalam keperawatan yang tidak bisa dilakukan secara mandiri. Inovasi intervensi EMAS bukan hanya dilakukan di Kelurahan Cisalak Pasar, akan tetapi juga sudah diadopsi seluruh wilayah Kota Depok dalam sistem pelaporan kegiatan posbindu PTM melalui google form.

\section{KESIMPULAN DAN SARAN}

Pengabdian masyarakat ini mendapatkan hasil bahwa terjadi perubahan perilaku dan kontrol gula darah dewasa dengan diabetes mellitus tipe 2 melalui intervensi EMAS (edukasi, manajemen nutrisi, aktivitas fisik, dan pengelolaan stres), oleh karena itu, dalam memberikan intervensi harus disesuaikan dengan penatalaksanaan penyakit dan kebutuhan penderita.

Program terkait upaya promotif dan preventif perlu ditinjau kembali dengan lebih memperhatikan aspek karakteristik dewasa dengan diabetes mellitus dan wilayah sebagai percontohan. Dinas kesehatan juga perlu melakukan integrasi terkait edukasi kesehatan yang diberikan kepada dewasa dengan diabetes mellitus menggunakan metode yang komprehensif sesuai dengan penatalaksanaan DM, dan memanfaatkan berbagai macam media yang lebih interaktif dan aplikatif, baik untuk tenaga kesehatan sendiri maupun dewasa dengan diabetes mellitus yang berfokus untuk meningkatkan pengetahuan, sikap, keterampilan, dan kontrol gula darah. Pelayanan keperawatan kesehatan masyarakat perlu dibentuk dalam setiap tatanan pelayanan kesehatan guna dapat lebih tepat menentukan intervensi apa yang sesuai dengan masalah masyarakat.

\section{DAFTAR PUSTAKA}

[1] K. Ayele, B. Tesfa, L. Abebe, T. Tilahun, and E. Girma, "Self care behavior among patients with diabetes in Harari, Eastern Ethiopia: the health belief model perspective," PLoS One, p. 7(4):e35515, 2012.

[2] S. Mohebi, M. Parham, E. Pour, and A. Kamran, "Self-care assessment in patients with diabetes in qom city in 2013," Arch Hyg Sci, 2013.

[3] Kemenkes, Info Datin: Waspada Diabetes. Pusat Data dan Informasi Kementrian Kesehatan RI, 2016.

[4] K. L. Joiner, S. Nam, and R. Whittemore, "Lifestyle interventions based on the diabetes prevention program delivered via eHealth: A systematic review and metaanalysis," Prev. Med. (Baltim)., vol. 100, pp. 194-207, 2017.

[5] Wattanakul, "Factors influencing diabetes self management behaviors among patients with T2DM in rural Thailand," Univ. Illinois Chicago, 2012.

[6] S. A. S. H. N. A. R. P. S. K. S. A. M. H. S. D. L. A. S. B. P. Y. A. L. D. P. N. N. S. M. R. S. M. P. D. Zufry, Konsensus Pengelolaan Dan Pencegahan Diabetes Melitus Tipe 2 Di Indonesia 2015. 2015. 
[7] A. Al-Khalifa, T. C. Mathew, N. S. Al-Zaid, E. Mathew, and H. M. Dashti, "Therapeutic role of low-carbohydrate ketogenic diet in diabetes," Nutrition, vol. 25, no. 11-12, pp. 1177-1185, 2009

[8] M. Ahdizadeh, N. Peymam, A. Taghipour, H. Esmaily, and S. Mahdizade, "Effect of health education program on promoting physical activity among diabetic women in Mashhad, Iran: applying social cognitive theory. J Res Health Sci," p. 13(1):90-7, 2013

[9] A. Dwi, A. Amatayakul, and S. Karuncharernpanit, "International Journal of Nursing Sciences Predictors of diabetes self-management among type 2 diabetics in Indonesia: Application theory of the health promotion model," Int. J. Nurs. Sci., vol. 4, no. 3, pp. 260-265, 2017.

[10] L. Fan, R. N. Cde, and S. Sidani, "Factors Influencing Preferences of Adult with Type 2 Diabetes for Diabetes SelfManagement Education Interventions," Can. J. Diabetes, 2018.

[11] C. S. Darling-Fisher, P. P. Kanjirath, M. C. Peters, and W. S. Borgnakke, "Oral Health: An Untapped Resource in Managing Glycemic Control in Diabetes and Promoting Overall Health," J. Nurse Pract., vol. 11, no. 9, pp. 889-896, 2015

[12] L.-W. Wang, S.-H. Ou, C.-S. Tsai, Y.-C. Chang, and C.-W Kao, "Multimedia exercise training program improves distance walked, heart rate recovery, and self-efficacy in cardiac surgery patients. J Cardiovasc Nurs," p. 31(4):3439, 2016.

[13] H. Lari, R. Tahmasebi, and A. Noroozi, "Diabetes \& Metabolic Syndrome: Clinical Research \& Reviews Effect of electronic education based on health promotion model on physical activity in diabetic patients," Diabetes Metab. Syndr. Clin. Res. Rev., pp. 6-11, 2017.

[14] X. Liang et al., "Effect of mobile phone intervention for diabetes on glycaemic control: a meta-analysis," $p$ 28(4):455-63, 2011

[15] P. Khaikleng, S. Wongwanich, K. Sriklaub, and H. Ajpru, "A training module for evaluation capacity building of a health support organisation in Thailand," vol. 171, pp. 1395-1399, 2015

[16] B. B. Rider, S. C. Lier, T. K. Johnson, and D. J. Hu, "Interactive Web-Based Learning," vol. 50, no. August 2014, pp. 122-128, 2016.

[17] I. Octa P, K. Tjahjono D.K., and A. Nuggetsiana S, "Pengaruh Frekuensi Konseling Gizi dan Gaya Hidup Terhadap Indeks Massa Tubuh, Lingkar Pinggang, Tekanan Darah, dan Glukosa Darah pada Penderita Diabetes Mellitus," pp. 1-19, 2011

[18] L. O. Gostin, H. Abou-taleb, S. A. Roache, and A. Alwan, "Legal priorities for prevention of non-communicable diseases : innovations from WHO 's Eastern Mediterranean region," Public Health, vol. 144, no. 202, pp. 4-12, 2016.

[19] J. Tuomilehto, J. Lindstr, and J. Eriksson, "STANDARDS OF MEDICAL CARE IN DIABETES - 2017 Standards of Medical Care in Diabetes d 2017," vol. 40, no. January, 2017.

[20] M. Hein, J. Lanquart, G. Loas, P. Hubain, and P. Linkowski, "Author ' s Accepted Manuscript sleep examinations," Psychosomatics, 2017.

[21] J. J. Joseph et al., "Modifiable Lifestyle Risk Factors and Incident Diabetes in African Americans," Am. J. Prev. Med. vol. 53, no. 5, pp. e165-e174, 2017.
[22] S. Spurr, J. Bally, C. Bullin, and K. Trinder, "Journal of Pediatric Nursing Type 2 Diabetes in Canadian Aboriginal Adolescents: Risk Factors and Prevalence," J. Pediatr. Nurs., vol. 36, pp. 111-117, 2017.

[23] S. K. Trisnawati and S. Setyorogo, "Faktor Risiko Kejadian Diabetes Melitus Tipe II Di Puskesmas Kecamatan Cengkareng Jakarta Barat Tahun 2012,’ J. Ilm. Kesehat., vol. 5, no. 1, pp. 6-11, 2013.

[24] D. F. Polit and C. T. Beck, Essentials of Nursing Research Appraising Evidence for Nursing Practice, Seventh Ed. China: Library of Congress Cataloging in Publication Data, 2010 .

[25] S. Dahlan, Statistik Untuk Kedokteran dan Kesehatan, 6th ed. Jakarta: Epidemiologi Indonesia, 2014

[26] M. Stanhope and J. Lancaster, Foundations of Nursing in The Community: Community-Oriented Practice. by Mosby, Inc., an affiliate of Elsevier Inc., 2016

[27] F. Eliana, "Penatalaksanaan DM Sesuai Konsensus Perkeni 2015," SATELIT Simp. 6.1 DM Updat. DAN HblC, pp. 1-7, 2015.

[28] M. S. Herring, E. A. Beckett, C. A. Stanton-robinson, and M. J. Witry, "What do I eat? Impact of an interactive teaching method for improving pharmacy students ' diabetes nutrition knowledge and comfort in providing nutrition counseling," Curr. Pharm. Teach. Learn., no. August 2017, pp. 0-1, 2018.

[29] T. S. Alghafri et al., "Health professionals' perceptions about physical activity promotion in diabetes care within primary health care settings in Oman," Heliyon, vol. 3, no. 12, p. e00495, 2017.

[30] G. Ruben, J. Rottie, and M. Y. Karundeng, "Pengaruh Senam Kaki Diabetes Terhadap Perubahan Kadar Gula Darah Pada Pasien Diabetes Melitus Tipe 2 Di Wilayah Kerja Puskesmas Enemawira," eJournal Keperawatan (eKp), vol. 4, pp. 1-5, 2016

[31] I. Mangiwa, Mario E. Katuk, and Lando Sumarauw, "Pengaruh Senam Kaki Diabetes Terhadap Nilai Ankle Brachial Index Pada Pasien Diabetes Melitus," eJournal Keperawatan, vol. 5, 2017.

[32] Sulidah, A. Yamin, and R. D. Susanti, "Pengaruh Latihan Relaksasi Otot Progresif terhadap Kualitas Tidur Lansia The Effect of Progressive Muscle Relaxation Exercise towards Older People 's Quality of Sleep," Fak. Keperawatan, Univ. Padjadjaran, vol. 4, no. April, pp. 11-20, 2016.

[33] A. Furqan, "Pengaruh Terapi Relaksasi Progresif Terhadap Stres Pada Remaja Penghuni Lembaga Pemasyarakatan Kota Samarinda," eJournal Psikol., vol. 5, no. 2, pp. 115124, 2017. 